\title{
LEGITIMIDADE, GOVERNANÇA CORPORATIVA E DESEMPENHO: ANÁLISE DAS EMPRESAS DA BM\&F BOVESPA
}

\author{
LEGITIMACY, CORPORATE GOVERNANCE AND PERFORMANCE IN BM\&F BOVESPA \\ LEGITIMIDAD, GOBIERNO CORPORATIVO Y DESEMPEÑO: ANÁLISIS DE LAS EMPRESAS DE LA BM\&F BOVESPA
}

\begin{abstract}
RESUMO
Neste artigo, avaliamos como a legitimidade condiciona o valor de mercado das empresas listadas na BM\&F Bovespa. Especificamente, analisamos como a adesão ao Novo Mercado modera o efeito da legitimidade no valor da empresa. Para tanto, investigamos 348 organizações, entre os anos de 2002 e 2007, o que gerou um total de 1.357 observações. Verificamos que a adesão ao Novo Mercado, o prestígio dos conselheiros e a reputação da empresa afetam significativamente o valor de mercado. Quando seccionadas as organizações de acordo com o nível de governança, verificamos que
\end{abstract}

as origens cultural-cognitivas e normativas da legitimidade afetaram significativamente o valor de mercado nos grupos com menor grau de governança, enquanto que entre as empresas do Novo Mercado a influência não foi significativa. Diante desses resultados, podemos concluir que a legitimidade é um importante fator de explicação da variabilidade do desempenho de empresas de capital aberto, em que a presença em listagens diferenciadas de governança condicionou a influência das demais origens da legitimidade no valor de mercado.

PALAVRAS-ChaVE Desempenho, governança corporativa, legitimidade, valor de mercado, bolsa de valores.

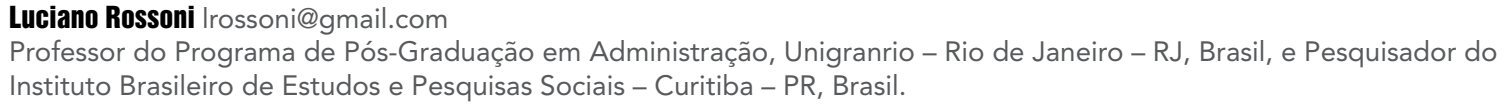

Clovis L. Machado-da-Silva (in memoriam)

Abstract This paper assesses how legitimacy conditions the market value of companies listed on the BM\&F Bovespa. We specifically analyze how joining the Novo Mercado moderates the effect of legitimacy on company value. For such, 348 organizations were investigated between 2002 and 2007, which generated a total of 1357 observations. Adherence to the Novo Mercado, the prestige of board members and company reputation significantly affect market value. When the organizations are divided in accordance with the level of governance, cultural-cognitive origins and legitimacy standards are seen to significantly affect market value in groups with a lower degree of governance, whereas among Novo Mercado companies, the influence was not as significant. In face of these results, legitimacy is shown to be an important factor in explaining variability in the performance of publicly traded companies and the presence in differentiated listings of governance conditioned the influence of other origins of legitimacy in market value.

keywords Performance, corporate governance, legitimacy, market value, stock exchange.

Resumen En este artículo, evaluamos cómo la legitimidad condiciona el valor de mercado de las empresas listadas en la BM\&F Bovespa. Especificamente, analizamos cómo la adhesión al nuevo mercado modera el efecto de la legitimidad en el valor de la empresa. Para ello, investigamos 348 organizaciones, entre los años 2002 y 2007, lo que generó un total de 1.357 observaciones. Verificamos que la adhesión al nuevo mercado, el prestigio de los consejeros y la reputación de la empresa afectan significativamente el valor de mercado. Al seccionar las organizaciones de acuerdo con el nivel de gobierno, verificamos que los orígenes cultural-cognitivo y normativo de la legitimidad afectaron significativamente el valor de mercado en los grupos con menor grado de gobierno, mientras que entre las empresas del nuevo mercado esa influencia no fue significativa. Ante dichos resultados, podemos concluir que la legitimidad es un importante factor de explicación de la variabilidad del desempeño de empresas de capital abierto, en que la presencia en listados diferenciados de gobierno condicionó la influencia de los demás orígenes de la legitimidad en el valor de mercado.

Palabras clave Desempeño, gobierno corporativo, legitimidad, valor de mercado, bolsa de valores. 


\section{INTRODUÇÃO}

No campo de estudo da estratégia, explicações acerca do desempenho das organizações tendem a dar primazia ora aos aspectos ligados à posição de uma empresa no setor, uma visão microeconômica, ora às questões acerca de como as organizações combinam seus recursos, uma visão baseada em recursos. No entanto, tanto uma perspectiva quanto outra tendem a enfatizar os elementos relacionados à dimensão racional-utilitária, em detrimento dos aspectos sociais que envolvem a atividade empresarial. Ora, se as organizações fazem parte de um sistema social mais amplo, cujas atitudes são avaliadas com base em um conjunto de crenças, valores e pressupostos, é provável que o julgamento, a aceitação e a credibilidade dessas organizações perante seus diversos stakeholders condicionem a capacidade de elas adquirirem recursos. Sendo assim, partindo de uma perspectiva organizacional e sociológica da estratégia (KIRSCHBAUM e GUARIDO FILHO, 2011; RUEF, 2003), entendemos que o desempenho das organizações não seja somente resultado de uma combinação de recursos em contextos econômicos determinados, mas também condicionado pela capacidade de validarem suas atitudes perante suas audiências, tendo como base critérios legitimamente aceitos na sociedade. Em poucas palavras, enfatizamos, neste estudo, que aquelas organizações que incorporam elementos legítimados no ambiente tendem a ser vistas como legítimas (MEYER e ROWAN, 1977), o que, por sua vez, as leva a gozar de maiores chances de sobrevivência e de angariar recursos (PARSONS, 1956; PFEFFER e SALANCIK, 1978).

Com base em tais apontamentos sobre a relação entre legitimidade e desempenho, escolhemos um campo de pesquisa com os elementos necessários para se fazer uma investigação que envolvesse o caráter multifacetado da legitimidade organizacional. Por isso, escolhemos pesquisar o mercado acionário brasileiro. Como alguns autores apontam (CARVALHO e PENNACCHI, 2012; LA PORTA e outros, 1998), mercados emergentes e de tradição legal francesa, como é o caso do Brasil, tendem a apresentar pouca proteção aos investidores, abrindo espaço para várias assimetrias. Diante dos riscos e incertezas emanados da baixa segurança do ambiente legal, pressupomos que os investidores pautam suas decisões em outros artefatos legitimados no mercado de capitais (ROSSONI e MACHADO-DA-SILVA, 2010), como listagens diferenciadas (CARVALHO e PENNACCHI, 2012), con- selho de administração (HIGGINS e GULATI, 2006) e reputação (ROBERTS e DOWLING, 2002).

Em face do exposto, o objetivo deste artigo é avaliar como as diferentes origens da legitimidade organizacional (formal regulatória, cultural-cognitiva e normativa) condicionam o desempenho das empresas listadas na BM\&F Bovespa, com base no seu valor de mercado. Para tanto, em primeiro lugar, consideramos como uma das origens da legitimidade a participação em listagens diferenciadas de governança no Brasil: o Novo Mercado da BM\&F Bovespa. Enquadramos a participação nessas listagens como de natureza formal regulatória da legitimidade (SCOTT, 1995), pois ela está diretamente atrelada ao aval e ao controle normativo de uma organização externa sobre as demais, garantindo-lhes status diferenciado (CAPRON e GUILLÉN, 2009; FISS, 2008). Como consequência, esperamos que organizações que aderiram a tais listagens tenham melhor desempenho, já que estão associadas diretamente a melhores práticas de governança corporativa (AGUILERA e JACKSON, 2003). Em termos empíricos, outros estudos já avaliaram a relação entre níveis diferenciados e valor de mercado (CARVALHO e PENNACCHI, 2012; LAMEIRA, NESS JUNIOR, MACEDO-SOARES, 2007; PROCIANOY E VERDI, 2009; SILVEIRA, BARROS, FAMÁ, 2006; SILVEIRA e outros, 2010); no entanto alguns deles fundiram, em uma única variável, o Novo Mercado e o Nível 2, tal como nenhum deles incorporou dados mais recentes, em especial do ano de 2007, que apresentou o maior volume de ofertas públicas de ações no Novo Mercado. Ademais, também contribuímos com as áreas de estratégia e finanças, proporcionando uma explicação alternativa para a relação entre governança e desempenho, com base no institucionalismo organizacional (FISS, 2008) e na sociologia das finanças (CARRUTHERS e KIM, 2011; GRÜN, 2004).

Em segundo lugar, consideramos como uma das origens da legitimidade cultural-cognitiva a posição do conselho de administração em relação às demais empresas, com base no board interlocking. Mesmo não sendo novidade que os conselhos de administração são peças fundamentais na gestão corporativa (COHEN e DEAN, 2005; DAVIS, 1996; HIGGINS e GULATI, 2006) e que sua estrutura e processo apresentam efeitos significativos no valor de mercado (BLACK, CARVALHO, GORGA, 2012; BLACK e KIM, 2012; WINTOKI, LINCK, NETTER, 2012), pouco deles se ativeram a analisar, no contexto brasileiro, os efeitos de seu entrelaçamento por meio de conselheiros ligados a múltiplas organiza- 
ções (SANTOS e SILVEIRA, 2007; SANTOS, SILVEIRA, BARROS, 2012). Raros, também, são os estudos que consideraram tal entrelaçamento com base em métodos e teorias relacionais, comumente associadas a análise de redes sociais (MENDES-DA-SILVA e outros, 2008; MENDES-DA-SILVA, 2011). Em face desses limites, além de propor uma justificativa teórica dos efeitos do board interlocking no valor de mercado pautando-se na legitimidade do conselho (DAVIS, 1996; HIGGINS e GULATI, 2006; MIZRUCHI, 1996), avaliamos e comparamos a influência dos indicadores de redes em termos de sua abertura (lacunas estruturais) e de seu fechamento (coeficiente de agrupamento) no valor de mercado, tanto no Mercado Tradicional quanto nos mercados diferenciados. Adicionalmente, também como elemento cultural-cognitivo, testamos o efeito, no valor de mercado, da maior presença das empresas de capital aberto em listagens diferenciadas (densidade) como proxy da institucionalização das práticas de governança. Com esta análise, buscamos aproximar a literatura de estratégia e finanças do arcabouço analítico da ecologia populacional (HANNAN e CARROL, 1992) e do institucionalismo organizacional (ROSSONI e MACHADO-DA-SILVA, 2010; RUEF e SCOTT, 1998)

Em terceiro lugar, como origem da legitimidade normativa, que é derivada das normas e valores presentes no ambiente societário das organizações (ALDRICH e FIOL, 1994; RUEF e SCOTT, 1998), incorporamos, pioneiramente no Brasil, os efeitos da reputação das empresas de capital aberto no valor de mercado, indo ao encontro de estudos internacionais como os de Fombrun e Shanley (1990) e Roberts e Dowling (2002).

Por fim, além de avaliar o efeito direto das origens da legitimidade no valor de mercado, também investigamos sistematicamente como esses efeitos variam entre os diferentes níveis de governança da BM\&F Bovespa. Mais que isso, buscamos explicar, sob uma ótica institucional (FLIGSTEIN e CHOO, 2005; GORGA, 2004; ROSSONI e MACHADO-DA-SILVA, 2010), as razões pelas quais a presença das empresas no Novo Mercado - proxy da legitimidade formal regulatória - moderam a influência das demais origens da legitimidade no valor de mercado. Baseando-se na premissa de que os mercados de capitais, em especial nos países emergentes, apresentam características idiossincráticas (BLACK, CARVALHO, GORGA, 2012), argumentamos que fazer parte de listagens diferenciadas serve como mecanismo de salva-guardas aos investidores, principalmente em ambientes de pouca proteção legal (CARVALHO e PENNACCHI, 2012).
Como consequência, as demais origens da legitimidade, que poderiam sustentar maior valorização das ações das empresas listadas na bolsa, perdem ou reduzem seu efeito quando presentes nessas listagens, em especial no valor de mercado. Pelo contrário, entre organizações presentes no Mercado Tradicional, com pouca proteção aos investidores, defendemos que seus efeitos são maiores.

Para tanto, dividimos este estudo em mais quatro seções além desta breve introdução. Na primeira delas, delineamos o quadro teórico e as hipóteses. Na sequência, detalhamos os procedimentos metodológicos e as variáveis, cujos resultados são apresentados na seção seguinte. Por fim, discutimos os resultados, e concluímos o estudo apontando algumas implicações teóricas e práticas, assim como sugerimos estudos futuros.

\section{TEORIA E HIPÓTESES SOBRE LEGIMIDADE E DESEMPENHO}

No escopo do institucionalismo organizacional, a legitimidade vem sendo referenciada como o conceito mais importante (DEEPHOUSE e SUCHMAN, 2008; SCOTT, 1995; SUCHMAN, 1995). Isso porque, como primeiramente apontaram Parsons (1956) e Pfeffer e Salancik (1978), desde que as organizações usam recursos do ambiente, a sociedade constantemente avalia se suas atitudes são apropriadas e se seus produtos ou resultados são socialmente úteis, perante critérios legitimamente definidos. Dessa forma, a legitimidade organizacional é consequência da interpretação das atitudes com base em sua comparação com valores socialmente legítimos. Em face de tais apontamentos, entendemos que "legitimidade é a percepção ou pressuposição generalizada de que as ações de uma entidade são desejáveis ou apropriadas dentro de algum sistema socialmente construído de normas, valores, crenças e definições" (SUCHMAN, 1995, p. 574).

O problema elementar é que a legitimidade dessas entidades não é diretamente acessível. Por causa disso, convencionalmente, busca-se avaliar se uma organização é legítima ou não com base em seu vínculo com objetos e origens. Por objeto organizacional entendemos, por exemplo, aqueles atos, práticas, procedimentos, estrutura, que podem ser avaliados em termos de sua legitimidade (COHEN e DEAN, 2005; DEEDS, MANG, FRANDSEN, 2004; DEEPHOUSE e SUCHMAN, 2008; GALASKIEWICZ, 
1985; HIGGINS e GULLATI, 2006). Sendo assim, um objeto é considerado legítimo se ele faz referência a uma origem tida como legítima. Por sua vez, origens da legitimidade são as diferentes audiências internas e externas que observam as organizações, como o estado, a sociedade e a mídia, que atribuem algum tipo de avaliação em face de algum aspecto da vida social (MEYER e SCOTT, 1983; RUEF e SCOTT, 1998). Todavia, elas devem manter como referência sua congruência com "sistemas socialmente construído de normas, valores, crenças e definições” (SUCHMAN, 1995, p. 574, tradução nossa), e não com a simples opinião de um estrato social em particular.

Como consequência para as organizações, o grau em que elas estão relacionadas com origens e objetos considerados legítimos no ambiente reduz a turbulência e mantém a estabilidade, o que pode promover maiores chance de sucesso e sobrevivência (MEYER e ROWAN, 1977). Isso ocorre porque, ao incorporar elementos legitimados em sua estrutura, as organizações aumentam o compromisso dos participantes internos (funcionários, unidades etc.), assim como de seus constituintes externos (stockholders, público, estado, parceiros etc.), protegendo a organização de ter sua conduta questionada (DEEPHOUSE e SUCHMAN, 2008). Assim, diante desses apontamentos, derivamos o seguinte pressuposto: organizações tidas como legítimas tendem a ter maior possibilidade de sobrevivência e maior capacidade de angariar recursos, o que resulta em melhor desempenho.

O desempenho organizacional, por sua vez, é condicionado por aspectos ligados à natureza da organização em si (ALDRICH e RUEF, 2006), mas também pela própria diferenciação da legitimidade organizacional em três dimensões (SCOTT e outros, 2000): formal-regulatória, normativa e cultural-cognitiva, podendo cada uma delas afetar, de diferentes formas, o desempenho (RUEF e SCOTT, 1998).

\section{Legitimidade formal regulatória}

De modo geral, a base da legitimidade formal regulatória está na conformidade com as regras: organizações legítimas são aquelas legalmente estabelecidas ou de acordo com as leis, regimentos, regulamentos, regras, padrões e expectativas criadas por governos, agências reguladoras, associações profissionais e organizações influentes (SCOTT, 1995; SCOTT e outros, 2000).

No presente artigo, avaliamos o aspecto formal regulatório da legitimidade por meio da adoção de práticas de governança corporativa, que são "todo o conjunto de meios jurídicos, culturais e arranjos institucionais que determina o que as empresas de capital aberto podem fazer, quem pode controlá-las, como seu controle é exercido, e como os riscos e retornos das atividades das quais são responsáveis são alocadas" (BLAIR, 1995, p. 3, tradução nossa). Por conta das peculiaridades do mercado acionário nacional, tais práticas de governança foram institucionalizadas no País de modo singular, resultando em uma forma própria de governança: os mercados diferenciados, cujo nível maior de exigência é o Novo Mercado, possuindo outros dois com menor grau de exigência, os níveis 2 e 1 . Inspirada na experiência alemã (o neuer markt), em 11 de dezembro de 2000, a Bolsa de Valores de São Paulo (hoje BM\&F Bovespa) criou uma listagem separada de organizações, denominada Novo Mercado (RIBEIRO NETO e FAMÁ, 2002). Segundo Ribeiro Neto e Famá (2002, p. 35), o "Novo Mercado da Bovespa é uma seção destinada à negociação de companhias que se submetam [voluntariamente] a exigências mais avançadas em termos de direitos dos acionistas investidores e melhores práticas de governança corporativa". Como aponta a Bovespa (2009), "essas regras [...] ampliam os direitos dos acionistas, melhoram a qualidade das informações usualmente prestadas pelas companhias, bem como a dispersão acionária e, ao determinar a resolução dos conflitos societários por meio de uma Câmara de Arbitragem, oferecem aos investidores a segurança de uma alternativa mais ágil e especializada".

A criação de mercados alternativos destaca-se como um importante mecanismo para garantir que o conteúdo normativo das práticas de governança corporativa seja incorporado pelas organizações de capital aberto (FISS, 2008; ROSSONI e MACHADO-DA-SILVA, 2010). Além de possuir o caráter coercitivo das obrigações formais, a adesão a mercados diferenciados pode ser vista como fator que suporta e habilita a atuação das organizações de capital de aberto, já que ela garante maior grau de confiança do mercado, simplesmente por submetê-las ao conteúdo de uma regra aceita como legítima (CAPRON e GUILLÉN, 2009).

No caso específico do mercado de ações brasileiro, a adesão ao Novo Mercado aufere maior credibilidade dessas organizações perante investidores, já que existe a crença disseminada de que organizações que fazem parte desse mercado são mais bem gerenciadas, mais transparentes e mais confiáveis (RIBEIRO NETO e FAMÁ, 2002), o que tem impacto no valor de mer- 
cado de suas ações (SILVEIRA, 2006). Sendo assim, esperamos que as organizações que se adequam aos padrões formais de legitimidade, especificamente a adesão ao Novo Mercado, tenham maior desempenho em termos de valor de mercado, o que nos leva à seguinte hipótese:

H1: Empresas que fazem parte do Novo Mercado da $\mathrm{BM} \& F$ Bovespa apresentam maior valor de mercado.

\section{Legitimidade cultural-cognitiva}

A legitimidade cultural-cognitiva deriva da conformidade a modelos e padrões socialmente aceitos no ambiente organizacional (RUEF e SCOTT, 1998; SCOTT, 1995). Tais padrões são tomados como certos, cujas características são vistas como parte da realidade, ausente de julgamento, absolutamente necessárias ou inevitáveis (ALDRICH e RUEF, 2006; HANNAN e CARROL, 1992; SCOTT, 1995). O modelo cognitivo prevalecente prescreve a visão de mundo e como as ações são feitas. Assim, as organizações são legítimas por seguirem tais padrões. A legitimidade cognitiva indica qual é o jogo, a realidade socialmente construída pela maior parte dos participantes (ALDRICH e FIOL, 1994).

Há algumas formas de se avaliar a legitimidade cultural-cognitiva, ressaltando-se que, não necessariamente, elas captam sua lógica processual e interpretativa. Uma delas é a densidade de determinada forma organizacional (número de adotantes), que, na perspectiva da ecologia populacional, representa a natureza tida como certa (take-for-granted) da legitimidade (HANNAN e CARROL, 1992). Tal proposição, basicamente, deriva de Meyer e Rowan (1977), que apontam que a aquiescência a estruturas amplamente aceitas de alto valor cerimonial torna a posição de uma organização mais favorável. No caso do mercado acionário, supõe-se que, quanto maior o grau de adoção a práticas de governança corporativa (maior densidade), maior o grau de institucionalização de tal prática, já que esse processo aponta para a aceitação de um modelo socialmente desejado, portanto legítimo (MEYER e ROWAN, 1977).

Outra forma de se ver a legitimidade cultural-cognitiva é por meio da própria legitimidade, prestígio ou reputação dos conselheiros de administração (COHEN e DEAN, 2005; HIGGINS e GULATI, 2006). Como apontam Certo e Hodge (2007) e Higgins e Gulati (2006), a qualidade, o prestígio e a certificação dos conselheiros são indícios de sua legitimidade, já que o mercado toma como certo que bons executivos melhoram os resultados da organização, o que é comprovado por esses estudos. Entre as formas de avaliar a legitimidade originada do conselho, seguimos Mizruchi (1996), avaliando-a por meio da estrutura de relações, conhecida como board interlocking. Esses estudos partem da premissa de que bons conselheiros tendem a participar de maior número de organizações, tal como de diferentes grupos de organizações, sendo a centralidade e a posição desses conselheiros na rede indício de seu prestígio como executivo. Assim, aqueles conselheiros mais bem posicionados na rede tendem a ter maior capacidade de receber informação, recursos e conhecimento, por meio do seu acesso privilegiado a diferentes grupos não conectados entre si, ou seja, maior proporção de lacunas estruturais (BURT, 1992). Com efeito, aqueles conselheiros com maiores lacunas estruturais (structural holes) tendem a ser valorizados pelo mercado e investidores, já que sua presença no conselho de determinada organização aponta para a legitimidade de sua gestão (COHEN e DEAN, 2005; DAVIS, 1996; HIGGINS e GULATI, 2006). Entendemos, portanto, que aquelas organizações que apresentam maior parcela de lacunas estruturais, por meio de seus conselheiros, tendem a ter maior valor de mercado, o que nos levou à seguinte hipótese:

\footnotetext{
H2a: Quanto maior a proporção de lacunas estruturais (structural holes) do conselho administrativo, maior o valor de mercado da organização.
}

Adicionalmente, o prestígio de determinado conselheiro também pode ser evidenciado por meio de sua participação em grupos fechados, supostamente solidários, na expectativa de que a coesão entre eles leve a maior confiança, aumentando as chances de aquisição de vantagens (LIN, 2001). Com isso, se ele faz parte desses grupos fechados, é bem provável que tenha maior facilidade em acessar recursos de terceiros do que os membros fora desse agrupamento. $\mathrm{Na}$ premissa de que as organizações sejam seletivas em estabelecer relacionamentos, esperamos que aquelas imersas em grupos coesos, com base nos laços entre seus conselheiros (maior coeficiente de agrupamento), sejam mais bem avaliadas que as demais pelos investidores, levando-nos à seguinte hipótese:

H2b: Quanto maior o coeficiente de agrupamento do conselho administrativo, maior o valor de mercado da organização. 


\section{Legitimidade normativa}

A legitimidade normativa deriva das normas e valores da sociedade ou do ambiente social relevante para o negócio, apontando a organização como apropriada ou desejável perante tais normas ou valores (ALDRICH e FIOL, 1994; RUEF e SCOTT, 1998). As normas especificam como as coisas devem ser feitas, definindo quais meios são legítimos para se atingirem determinados fins; os valores concebem quais padrões são utilizados para comparar e acessar estruturas e práticas existentes (SCOTT, 1995). Sendo assim, uma organização é apropriada e desejada quando atende a tais normas e valores, obtendo uma avaliação normativa positiva da sociedade e de seus stakebolders (ALDRICH e RUEF, 2006; SUCHMAN, 1995).

Como as organizações atendem variavelmente a essas normas e valores, podemos diferenciá-las em termos de sua reputação, que nada mais é que a expectativa generalizada sobre o comportamento da firma, baseada em percepções coletivas acerca de seu passado (DEEPHOUSE e SUCHMAN, 2008), refletindo o sucesso de algumas organizações em suprir as expectativas de múltiplos stakeholders. Com efeito, se a reputação envolve o julgamento da audiência acerca do que é tolerável ou não como conduta, os termos desse julgamento são dados por aquilo que é legitimamente aceito como bom ou ruim. Dessa forma, se empresas tem uma boa reputação é porque elas incorporaram elementos legitimados no ambiente (DEEPHOUSE e SUCHMAN, 2008). No caso do mercado acionário, como apontam Fombrun e Shanley (1990), a interpretação dos investidores acerca da informação dada por cada organização operante no mercado é condicionada pelos pressupostos que eles têm sobre cada firma. Por isso, no mercado de ações, alguns fatos repercutem tão mal para algumas empresas e, para outras, nem tanto. Assim, esperamos que empresas de boa reputação, por serem consideradas legítimas, tenham maior valor de mercado, logo:

H3: Quanto maior a reputação da organização, maior o seu valor de mercado.

As hipóteses delineadas acima apontam para o fato de que cada uma das dimensões da legitimidade pode afetar, em maior ou menor grau, a dinâmica social. Isso é fato, por exemplo, quando analisamos o processo de modernização da sociedade: em quase todos os sistemas sociais, entre eles o mercado de capitais, é eminente a ênfase dada nos aspectos racionais de origem formal e regulatória do sistema, em detrimento de outras formas de vigência da legitimidade, como o tradicionalismo e o personalismo (KALBERG, 1980). Por causa disso, buscamos avaliar, neste estudo, o caráter moderador da legitimidade formal regulatória acerca da adesão das empresas no Novo Mercado nas outras origens da legitimidade. Primeiro, por causa da temporalidade do fenômeno: a adesão a mercados diferenciados de governança ocorreu posteriormente à existência de outras práticas no mercado acionário, que, por sua vez, são de origem cultural-cognitiva e normativa. Segundo, porque, diante do processo de modernização do mercado acionário brasileiro, fruto, em parte, da modernização econômica pela qual passou o Brasil nos últimos anos (RIBEIRO NETO e FAMÁ, 2002), existe uma tendência de os elementos de caráter racional utilitário e racional formal adquirirem caráter racional substantivo, ou seja, elas são sedimentadas como formas de vida, criando justificativas incorporadas como crenças, valores e normas, que suportam a ação racional pragmática dos agentes (vide KALBERG, 1980). No caso das práticas de governança, como esse sistema foi construído em mercados tidos como de referência para o mercado acionário brasileiro, seu conteúdo normativo era mais facilmente legitimado, já que a origem era vista como legítima (AGUILERA e JACKSON, 2003). Em um movimento inverso, as práticas tradicionais vigentes até momentos anteriores no mercado acionário brasileiro, e ainda vigentes, começaram a competir com esse novo padrão institucionalizado, cujo esse último tende a sobrepor o poder de explicação do primeiro. Portanto boa parte da influência existente pelas outras origens da legitimidade acaba sendo incorporada pela adoção dessas práticas diferenciadas de governança, perdendo parte de seu poder de explicação. Em termos mais específicos, propomos que o capital social do conselho, avaliado com base tanto nos laços fracos (lacunas estruturais) quanto nos laços fortes (coeficiente de agrupamento), não é tão relevante no Novo Mercado, pois a adoção das regras formais já assegura uma boa avaliação das empresas diante dos investidores. O mesmo vale para a densidade: a ubiquidade da adoção de práticas de governança pelas empresas de capital aberto tende a ter maior efeito entre aquelas que não as adotaram formalmente, ou seja, para aquelas fora do Novo Mercado. Como destacamos anteriormente, maior adoção significa que essas formas são tomadas como certas (RUEF e SCOTT, 1998), cujo efeito nos esquemas de 
avaliação dos investidores é dado pela crença na prática como algo socialmente válido, e não pela confiança na regra. Por fim, como a reputação envolve a diferenciação das organizações em relação às demais (DEEPHOUSE e SUCHMAN, 2008), caso as empresas façam parte de um mesmo status (presença no Novo Mercado), tal diferenciação tende a ter seu efeito no valor de mercado reduzido ou anulado. Perante tais afirmações, delineamos as seguintes hipóteses:

H4a: A presença no Novo Mercado da $B M E F$ Bovespa modera o efeito das lacunas estruturais (structural holes) no valor de mercado da empresa, de modo que, em sua presença, é menor o efeito das lacunas estruturais no valor de mercado.

H4b: A presença no Novo Mercado da BMEF Bovespa modera o efeito do coeficiente de agrupamento no valor de mercado da empresa de maneira que, em sua presença, é menor o efeito do coeficiente de agrupamento no valor de mercado.

H4c: A presença no Novo Mercado da BMEF Bovespa modera o efeito da densidade no valor de mercado da empresa de modo que, em sua presença, é menor o efeito da densidade no valor de mercado. H5: A presença no Novo Mercado da BMEF Bovespa modera o efeito da reputação no valor de mercado da empresa de maneira que, em sua presença, é menor o efeito da reputação no valor de mercado.
Em suma, afirmamos, neste artigo, que o desempenho (valor de mercado) das organizações de capital aberto listadas na BM\&F Bovespa é positivamente influenciado pela legitimidade formal regulatória, cultural-cognitiva e normativa das organizações. No entanto, como há maior orientação dentro do mercado de capitais por práticas formais de governança, esperamos que a adoção de tais práticas, como elemento que aufere legitimidade formal regulatória às organizações, modere o efeito das outras origens da legitimidade no desempenho das empresas. Tais afirmações podem ser visualizadas no esquema da Figura 1.

\section{DADOS, VARIÁVEIS E PROCEDIMENTOS METODOLÓGICOS}

Definimos como população deste estudo as companhias listadas na BM\&F Bovespa, restringindo nossa coleta a partir do ano de adesão das primeiras empresas ao Novo Mercado, que ocorreu em 2002. Considerando o total de empresas que divulgaram suas informações para o órgão regulador competente, a Comissão de Valores Mobiliários (CVM), obtivemos um total de 2.306 observações, que ocorreram entre os anos de 2002 e 2007 (intervalo de seis anos). Algumas dessas observações tiveram que ser remo-

\section{Figura 1 - Esquema analítico da relação entre legitimidade e desempenho}

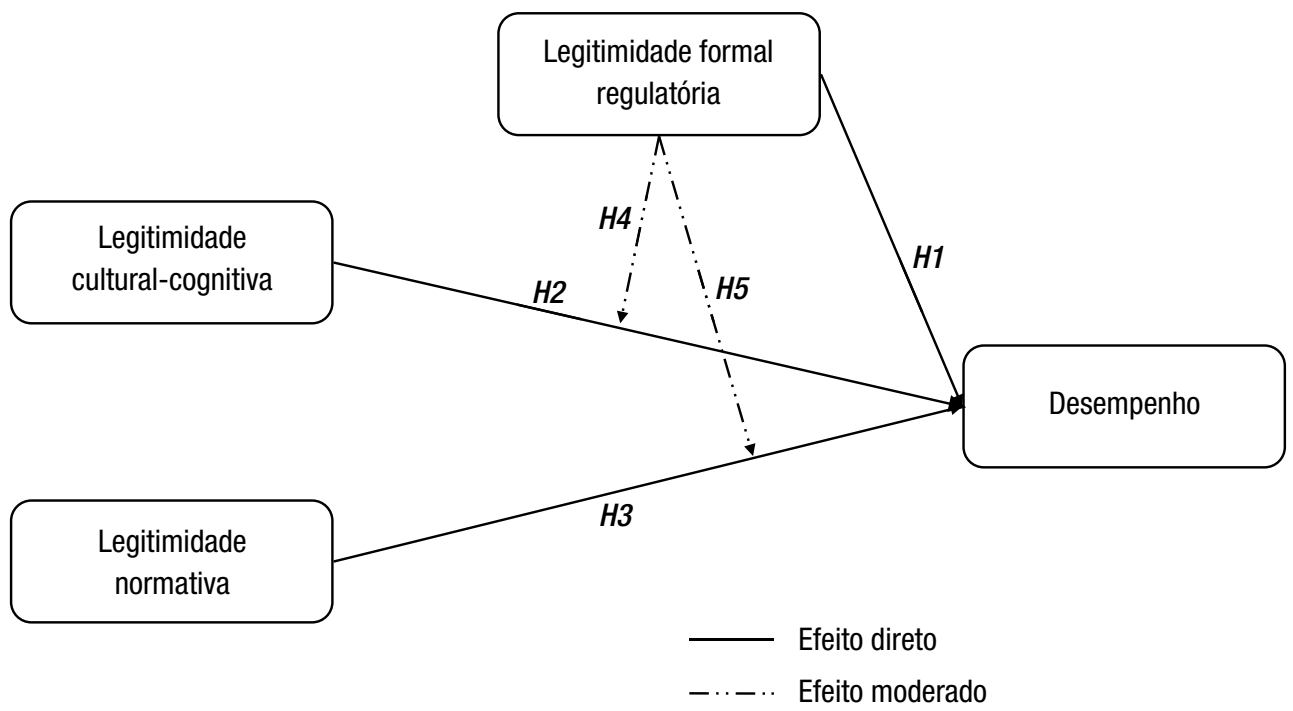


vidas, devido à ausência de informações na base de dados Economatica ${ }^{\circledR}$ ou por não apresentarem um nível mínimo de liquidez no mercado de ações. Assim, nossa amostra foi de 1.357 observações, geradas por 348 empresas. Coletamos os dados por meio do Sistema de Divulgação Externa (Divext) da CVM, da BM\&F Bovespa e do aplicativo Economatica ${ }^{\circledR}$. Entre as fontes documentais, listam-se a pesquisa anual sobre as Empresas Mais Admiradas no Brasil, realizada pela revista Carta Capital. Agregamos esses dados em planilhas, analisando-os por meio dos aplicativos UCINET e PAJEK, para a análise de redes, e STATA e GRETL, para a análise econométrica.

\section{Variável dependente}

Desempenho organizacional, em que, para o mercado acionário, utilizamos o $\mathrm{Q}$ de Tobin, que nos aponta $\mathrm{O}$ valor da empresa, tomando como base a soma do valor de mercado das ações da empresa e de seus débitos em relação ao valor contábil de seu ativo (CHUNG e PRUITT, 1994). Seguindo uma série de estudos anteriores (p. ex: CARVALHAL-DA-SILVA e LEAL, 2005; MENDES-DA-SILVA e outros, 2009; SILVEIRA, 2006), utilizamos a adaptação de Chung e Pruitt (1994, p. 72), que define formalmente a medida como: Tobin's $Q=(V M O+V M P+D I V T) / A T$, sendo $V M O=$ valor de mercado das ações ordinárias; $V M P=$ valor de mercado das ações preferenciais; $D I V T=$ valor contábil das dívidas de curto e longo prazos da empresa, mais especificamente a soma do passivo circulante com o exigível a longo prazo, subtraído do ativo circulante menos os estoques; $A T=$ valor contábil do ativo total da organização. Vale considerar que o desempenho organizacional é uma variável de segunda ordem, não podendo ser diretamente acessado (CARTON e HOFER, 2006). Por essas razões, para atender ao nosso objetivo, escolhemos, como medida de avaliação de desempenho no mercado acionário, o Q de Tobin, que nos indica o valor da empresa.

\section{Variável moderadora}

Legitimidade formal regulatória, avaliada pela participação no Novo Mercado, no Nível 2 e no Nível 1 de governança. Consideramos como categoria de comparação o Mercado Tradicional em relação às três variáveis dummy que criamos. Cada uma delas compreende exclusivamente as empresas participantes do mercado indicado (Novo Mercado, Nível 2 ou Nível
1), identificadas ano a ano, em que se assume valor igual a 1 , se a empresa participa de um nível, e valor 0 para os outros casos (vide, p. ex, MENDES-DA-SILVA e outros, 2009; PROCIANOY e VERDI, 2009; SILVEIRA, 2006). Como avaliamos a presença nos mercados diferenciados anualmente, nossos indicadores acompanharam a migração das empresas entre níveis, no período compreendido entre 2002 e 2007. Além disso, ressaltamos que testamos a Hipótese 1 com base no Novo Mercado.

\section{Variáveis independentes}

Legitimidade cultural-cognitiva, que foi operacionalizada por meio de dois tipos de indicadores. Um deles envolveu a estrutura de relações, conhecida como board interlocking. Utilizamos o método de análise de redes sociais para o compartilhamento de conselheiros e executivos entre organizações (vide, por exemplo, MENDES-DA-SILVA e outros, 2009; MENDES-DA-SILVA, 2011). Após a análise, duas medidas foram obtidas como indicadores da legitimidade originada do conselho: (1) lacunas estruturais e (2) coeficiente de agrupamento, obtidas por meio do software UCINET. O segundo tipo de indicador envolve a análise da institucionalização de formas organizacionais, (3) densidade da forma organizacional, que, em nosso caso, refere-se à adoção de níveis diferenciados de governança.

(1) Lacunas estruturais (structural holes), que são os relacionamentos não redundantes entre dois contatos (BURT, 1992). Assim, quanto menor o número de laços redundantes, maior o número de lacunas estruturais, havendo menor redundância de informação. Especificamente, utilizamos a medida de eficiência dos laços (BURT, 1992, p. 53), que mensura o número de contatos não redundantes EffSize em relação ao total de contatos $n$ de um ator $i$. Como trabalhamos com dados binários, utilizamos a forma simplificada de Borgatti (1997). Formalmente, considerando que um ator $i$ apresenta $n$ número de contatos, podemos avaliar o número de contatos redundantes por meio da equação $D_{\text {alters }}=2 \mathrm{l} / \mathrm{n}$, em que $l$ é o número de laços entre $n$ (alters). Já que $D_{\text {alters }}$ indica o total de laços redundantes, consideramos como laços não redundantes EffSize como $n-D_{\text {alters. }}$ Dessa forma, a proporção de laços não redundantes Efficiency é dado por EffSize/ $n$. Utilizamos essa medida por não apresentar alta correlação com o número de contatos e por sua representatividade em relação ao engajamento nos laços fracos. Como há variação anual de 
conselheiros que fazem parte das organizações, calculamos essa medida para cada ano de participação da empresa na bolsa.

(2) Coeficiente de agrupamento, que mede a densidade local da rede, em termos de seu aninhamento, indicando como os contatos de um ator estão recursivamente ligados entre si. Em outras palavras, quanto maior o número de cliques que eles formam (laços mútuos entre, no mínimo, três participantes), maior o agrupamento da rede. Formalmente, podemos definir o coeficiente de agrupamento CC como 3 x número de cliques/número de trios conectados. Ele pode variar de 0 a 1 , em que redes totalmente agrupadas apresentam coeficiente 1, enquanto aquelas totalmente desagrupadas apresentam coeficiente 0 . Calculamos essa medida para cada ano de participação da empresa na Bolsa.

(3) Densidade populacional. Refere-se ao número de organizações que apresentam determinada forma organizacional (ALDRICH e RUEF, 2006; HANNAN e CARROL, 1992), sendo ele proxy do grau de institucionalização. Seguindo estudos anteriores (ALDRICH e RUEF, 2006; DEEDS, MANG, FRANDSEN, 2004; FOMBRUN e SHANLEY, 1990; HANNAN e CARROL, 1992), nós operacionalizamos a densidade organizacional, apontando, em cada ano, o número de organizações que participaram dos mercados diferenciados da BM\&F Bovespa, somando o total de organizações de cada um dos três mercados, para gerar o escore de densidade.

Legitimidade normativa, que operacionalizamos por meio da reputação organizacional, assim como fizeram Deeds, Mang e Frandsen (2004), Deephouse e Carter (2005) e Fombrun e Shanley (1990). Utilizamos o escore das Empresas Mais Admiradas no Brasil, segundo pesquisa anual desenvolvida no País pela revista Carta Capital. A pesquisa, inspirada na The Most Admired Companies da revista americana Fortune (vide DEEPHOUSE e CARTER, 2005 e FOMBRUN e SHANLEY, 1990), incorpora a percepção do empresariado em relação a critérios econômicos e financeiros de empresas que atuam no Brasil, assim como aspectos relacionados à imagem (marca, atitudes, qualidade, administração etc.), envolvendo 1.224 casos por ano. Operacionalizamos essa variável considerando a posição da empresa no ranking geral das Empresas Mais Admiradas em cada um dos seis anos avaliados (2002-2007). No entanto destacamos somente as 20 primeiras da listagem, já que, a partir desse ponto, a discriminação entre elas é menos precisa. Destacamos, também, as melhores empresas de cada setor. Após isso, verificamos quais delas faziam parte da BM\&F
Bovespa, vinculando os resultados da pesquisa aos outros indicadores. Para manter a natureza ordenada da reputação (vide DEEPHOUSE e SUCHMAN, 2008), atribuímos o maior valor para empresas que alcançaram o primeiro lugar do ranking em determinado ano, diminuindo o valor em uma unidade para cada posição inferior (valor da variável $=22$ - posição no ranking). No caso das melhores do setor, quando não estavam entre as 20 primeiras da análise geral, atribuímos valor 1 , e, para todas as demais empresas, valor 0 .

\section{Variáveis de controle}

Tamanho da empresa. Avaliamos o tamanho da empresa em relação ao valor contábil do ativo total, (vide MENDES-DA-SILVA e outros, 2008; MENDES-DA-SILVA e outros, 2009; SILVEIRA, 2006), que foi logaritmizado. Tanto essa variável como as demais variáveis de controle foram incorporadas devido a seu uso corrente nos estudos de governança quando se refere aos efeitos no valor de mercado.

Idade. Definida pelo logaritmo natural dos anos de operação da empresa no mercado acionário brasileiro (vide MENDES-DA-SILVA e outros, 2009).

Alavancagem financeira. Dívida financeira total da organização em relação ao ativo total (CARVALHALDA-SILVA e LEAL, 2005; SILVEIRA, BARROS, FAMÁ, 2006). Vista como medida que relata a estrutura de capital da organização (SILVEIRA, 2006), ela aponta a extensão em que a organização utiliza capital de terceiros para financiar suas operações.

Setor. Seguindo estudos anteriores (PROCIANOY e VERDI, 2009; SILVEIRA, 2006), controlamos o efeito do setor, já que existe evidência de que ele é antecedente de diversas variáveis utilizadas (vide SILVEIRA, BARROS, FAMÁ, 2006). Para tanto, criamos ( $s-1)$ variáveis dummy em que $s$ é o número de setores identificados no Economatica ${ }^{\circledR}$, considerando como categoria de referência o setor outros.

\section{Procedimentos de análise}

Análise de dados em painel. De maneira intuitiva, os dados em painel são utilizados quando temos vários casos $(N)$ com um número razoável de observações no tempo ( $T$ ), configurando-se em $N \times T$ observações (GREENE, 2000). Três categorias de modelos econométricos de regressão podem ser empregados: o agrupamento de dados de corte com base nos Mínimos Quadrados Ordinários (MQO agrupado), os efeitos 
fixos $(E F)$ e os efeitos aleatórios ( $E A)$. Segundo Greene (2000), a escolha depende do ajuste do modelo aos pressupostos, que são avaliados por meio de três hipóteses: (a) a existência ou não de um único intercepto das unidades de corte transversal (avaliada por meio do teste de F de Chow); (b) se a variância do intercepto é igual a zero (teste Multiplicador de Lagrange modificado pela proposição de Breusch e Pagan); (c) se os estimadores são consistentes de acordo com a estimação dos Mínimos Quadrados Generalizados (teste de Hausman). Pela avaliação dessas hipóteses, escolhemos o melhor modelo para cada uma das relações entre variáveis. Também avaliamos se os modelos apresentavam problemas de heterocedasticidade, por meio do teste de White. No caso de a hipótese nula ser verdadeira, não há problema de heterocedasticidade. Repetimos tais procedimentos para cada uma das subamostras utilizadas.

Análise da moderação. Para evitar problemas de colinearidade dos coeficientes gerados pela avaliação da moderação por meio da interação de variáveis, utilizamos o procedimento de Arnold (1982), que consiste em dividir a amostra em grupos, que, em nosso caso, foram três: um composto por empresas participantes do Novo Mercado; outro de empresas participantes do Nível 1 e do Nível 2 de governança; outro formado por empresas do Mercado Tradicional. Após isso, feitas as análises de dados em painel, os coeficientes das variáveis independentes para cada um dos grupos foram comparados entre si por meio do teste Qui-quadrado, cuja fórmula dispõe-se abaixo:

$$
\operatorname{chi}_{\text {emp }}^{2}=\frac{\left(\text { beta }_{2}-\text { beta }_{1}\right)^{2}}{\left(\mathrm{se}_{2}^{2}-\mathrm{se}_{1}^{2}\right)}
$$

Em que o valor do beta1 é o coeficiente da variável independente do grupo 1; o valor do beta2 é o coeficiente da variável independente do grupo 2; $s e_{1}$ é o erro padrão do coeficiente do grupo $1 ; s e_{2}$ é o erro padrão do coeficiente do grupo 2. Com o valor do Qui-quadrado calculado para cada uma das comparações entre dois grupos, aceitamos o efeito moderador quando a probabilidade de erro do teste foi baixo. Para efeitos do teste das Hipóteses 4 e 5 , comparamos os resultados do grupo de empresas do Novo Mercado com os do Mercado Tradicional. Adicionalmente, fizemos a comparação entre as empresas do Novo Mercado com as empresas dos níveis 1 e 2. Nenhum dos modelos apresentou problemas de multicolinearidade, o que pode ser verificado pelos fatores de inflação da variância (VIF) menores que 5 .

Robustez dos resultados, endogeneidade e causalidade. Após a especificação do modelo mais adequado para cada uma das análises, verificamos a robustez dos resultados de quatro formas. Assim como feito por Silveira e outros (2010), primeiramente, avaliamos a existência de problemas de colinearidade entre as variáveis independentes. Depois, observamos se os resultados mantinham-se consistentes quando regredimos os modelos sem as variáveis não significativas, tal como verificamos se eles apresentavam a mesma tendência sem os outliers. Quando possível, avaliamos a influência das variáveis independentes usando outros indicadores. No caso da reputação, usamos uma variável dummy para avaliar se as empresas citadas na pesquisa das mais admiradas apresentavam maior valor de mercado, sendo consistentes com os resultados que encontramos. No caso das lacunas estruturais, usamos outro indicador, a eficácia (vide BURT, 1992), e, para o coeficiente de agrupamento, a densidade local (vide BORGATTI, 1997), em que ambos foram consistentes. Por fim, para a variável densidade, fizemos a contagem considerando a presença de empresas somente no Novo Mercado e conjuntamente no Novo Mercado e no Nível 2, em que os resultados foram compatíveis.

No que tange à endogeneidade, quase a totalidade da literatura sobre governança aborda algum problema envolvendo qualquer indicador relacionado a performance, índices de governança e estrutura de capital (WINTOKI, LINCK, NETTER, 2012). Isso porque esses elementos apresentam tanto características de autosseleção quanto de causalidade reversa (LI e PRABHALA, 2007), sendo normalmente tratados por modelos com variáveis instrumentais ou equações simultâneas (vide, p. ex, BLACK e KIM, 2012; SILVEIRA e outros, 2010). Mesmo na presença desses problemas, não há na literatura nem tratamento, nem relação plausível de endogeneidade que envolva listagens diferenciadas, como pode ser visto nos estudos de Carvalho e Pennacchi (2012) e de Procianoy e Verdi (2009). Sobre os indicadores relacionais utilizados para avaliar a posição do conselho na estrutura relacional, deve-se destacar que eles são bem distintos dos indicadores de estrutura do conselho, pois sua conformação é notoriamente exógena. Assim, não há evidências claras na literatura acerca de sua endogeneidade (MIZRUCHI, 1996). O mesmo vale para a reputação, que também apresenta natureza exógena, cuja avaliação vai além dos limites do mercado de capitais. 


\section{RESULTADOS}

Os resultados podem ser vistos na Tabela 1 , sendo que os resultados para a amostra completa estão no Modelo 1.Nele, optamos pelo modelo fixo de dados em painel com erro robusto, porque o Teste de White apontou problemas de heterocedasticidade $(\mathrm{p}<0,001)$, o Teste $\mathrm{F}$ de Chow $(\mathrm{p}<0,001)$ indicou que os coeficientes gerados por meio dos mínimos quadrados ordinários não são consistentes, e o Teste de Hausman apontou para melhor ajuste dos estimadores desenvolvidos no modelo fixo $(\mathrm{p}<0,001)$. O Modelo 1 mostrou-se com excelente poder de explicação $\left(R^{2}=86,7 \%\right)$, em que, entre as variáveis de controle, podemos verificar que a idade da empresa ( $\operatorname{n}$ do tempo em bolsa) afetou significativamente o valor da empresa. Em média, o incremento de um ano aumenta em 0,15 ponto $(\ln (1,156))$ o valor de mercado da empresa. Isso significa que empresas com maior tempo de atuação no mercado tendem a ser mais valorizadas que as demais. A alavancagem financeira também tem efeito significativo no valor da empresa. Na média, para cada unidade no incremento da razão entre dívida/ativo, as empresas tendem a ter um aumento de 0,6\% em seu valor. No caso desse indicador, pode soar estranho que empresas mais endividadas sejam mais valorizadas. No entanto, o grau de endividamento indica que uma organização consegue captar maior quantidade de recursos, sem que isso signifique, na percepção do mercado, risco de insolvência. Sendo assim, essa relação positiva entre os dois indicadores pode apontar para maior credibilidade dessas organizações, o que lhes aufere poder de barganha com as fontes de financiamento, assim como menor risco percebido, fato que pode ser avaliado em estudos futuros. Já entre os indicadores relacionados com a legitimidade formal regulatória, podemos verificar que aquelas organizações que fazem parte do Novo Mercado apresentam, em média, 69\% a mais de valorização que as empresas que fazem parte do Mercado Tradicional, suportando a Hipótese 1. Todavia, os outros níveis de governança não se mostraram significativos, indicando que a influência desses mitos legitimadores ocorre somente no nível mais alto de exigência. No caso dos indicadores relacionados à legitimidade cultural-cognitiva, somente a proporção de laços não redundantes do conselho mostrou-se significativa, corroborando a Hipótese 2a e levando-nos a refutar a Hipótese 2b. Em média, para um aumento de 50\% na proporção de laços não redundantes, há um aumento de 10,8\% no valor de mercado da empresa. Considerando a reputação como indicador da legitimidade normativa, verificamos que o aumento em uma posição no ranking das empresas mais admiradas proporciona, em média, um aumento de 5,5\% no valor de mercado $(\mathrm{p}=0,002)$, corroborando a Hipótese 3. Nos Modelos 2, 3 e 4, fizemos as análises das mesmas variáveis, no entanto dividimos a amostra em grupos distintos a partir do nível de governança, fato que levou à ausência dessas variáveis nos modelos. Com base nos resultados dos testes de ajuste dos estimadores e dos erros, selecionamos aqueles mais adequados, em que todos exigiram erros padrão robustos, painéis fixos nos Modelos 2 e 4 e painel aleatório no Modelo 3. No Modelo 2, que envolve somente as empresas que fazem parte do Novo Mercado, nenhuma das variáveis mostrou-se significativa, indo ao encontro do esperado, já que acreditamos que o fato de essas empresas serem certificadas por um artefato fortemente legitimado reduz ou anula a influência das demais origens da legitimidade. Entre as empresas com níveis intermediários de governança (Modelo 3), verificamos que todas as variáveis mostraram-se significativas, com exceção das lacunas estruturais. Isso remete de maneira clara que, na ausência da legitimidade formal regulatória atribuída por meio da governança corporativa, as outras origens da legitimidade ganham valor explicativo. Por fim, no Modelo 4, podemos ver que todas variáveis que se referem às origens da legitimidade cultural-cognitiva e normativa afetam significativamente o valor de mercado das organizações, o que aponta para influência destacada dessas variáveis na ausência da adesão ao nível mais alto de governança. Tais diferenças de influência entre os diversos níveis de governança são destacadas nas comparações entre os Modelos 2, 3 e 4 (duas últimas colunas da Tabela 1). No caso das lacunas estruturais, a diferença entre os coeficientes do Modelo 2 e do Modelo 4 é de 0,202 ponto, indicando que sua influência é maior entre empresas do Mercado Tradicional do que entre empresas do Novo Mercado. Somando ao fato de ela ser significativa somente no Mercado Tradicional e não no Novo Mercado, corroboramos a Hipótese 4a. No caso do coeficiente de agrupamento, apesar de os coeficientes serem significativos nos Modelos 3 e 4, ao contrário do esperado, a influência dessa variável é negativa entre empresas que não fazem parte do Novo Mercado, levando-nos a refutar a Hipótese $4 \mathrm{~b}$. Sobre a densidade, verificamos que há relação significativa entre o aumento no número 


\begin{tabular}{|c|c|c|c|c|c|c|}
\hline Nível de governança: & $\begin{array}{l}\text { Amostra } \\
\text { completa }\end{array}$ & $\begin{array}{c}\text { Novo } \\
\text { Mercado }\end{array}$ & Niveis 1 e 2 & $\begin{array}{l}\text { Mercado } \\
\text { Tradicional }\end{array}$ & $\begin{array}{l}\text { Moderação N. } \\
\text { Merc. x Níveis } \\
1 \text { e } 2\end{array}$ & $\begin{array}{c}\text { Moderação } \\
\text { N. Merc. X } \\
\text { Tradicional }\end{array}$ \\
\hline & Modelo 1 & Modelo 2 & Modelo 3 & Modelo 4 & Modelos 2 × 3 & Modelos $2 \times 4$ \\
\hline \multicolumn{7}{|l|}{ Variáveis independentes } \\
\hline Novo Mercado (Dummy) & $\begin{array}{c}0,690^{\star \star *} \\
(0,210)\end{array}$ & & & & & \\
\hline Nível 2 (Dummy) & $\begin{array}{c}0,158 \\
(0,111)\end{array}$ & & & & & \\
\hline Nível 1 (Dummy) & $\begin{array}{c}0,170 \\
(0,129)\end{array}$ & & & & & \\
\hline Structural holes & $\begin{array}{c}0,217^{\star \star \star} \\
(0,063)\end{array}$ & $\begin{array}{l}-0,006 \\
(0,146)\end{array}$ & $\begin{array}{c}0,070 \\
(0,082)\end{array}$ & $\begin{array}{c}0,195^{\star \star \star} \\
(0,070)\end{array}$ & $\begin{array}{c}0,076 \\
{[0,208]}\end{array}$ & $\begin{array}{c}0,202 \\
{[1,548]}\end{array}$ \\
\hline Coeficiente de agrupamento & $\begin{array}{l}-0,046 \\
(0,063)\end{array}$ & $\begin{array}{c}0,252 \\
(0,214)\end{array}$ & $\begin{array}{c}-0,159^{\star \star} \\
(0,080)\end{array}$ & $\begin{array}{l}-0,144^{*} \\
(0,079)\end{array}$ & $\begin{array}{l}-0,412^{\star} \\
{[3,235]}\end{array}$ & $\begin{array}{l}-0,397^{\star} \\
{[3,017]}\end{array}$ \\
\hline Densidade & - & $\begin{array}{l}-0,001 \\
(0,003)\end{array}$ & $\begin{array}{c}0,002^{\star \star \star} \\
(0,001)\end{array}$ & $\begin{array}{c}0,005^{\star \star \star} \\
(0,001)\end{array}$ & $\begin{array}{c}0,002 \\
{[0,757]}\end{array}$ & $\begin{array}{l}0,005^{*} \\
{[3,155]}\end{array}$ \\
\hline Reputação & $\begin{array}{c}0,055^{\star \star \star} \\
(0,018)\end{array}$ & $\begin{array}{l}-0,260 \\
(0,338)\end{array}$ & $\begin{array}{l}0,042^{\star \star \star} \\
(0,0132)\end{array}$ & $\begin{array}{c}0,050^{\star \star \star} \\
(0,012)\end{array}$ & $\begin{array}{c}0,303 \\
{[0,799]}\end{array}$ & $\begin{array}{c}0,311 \\
{[0,844]}\end{array}$ \\
\hline \multicolumn{7}{|l|}{ Variáveis de controle } \\
\hline Idade (In) & $\begin{array}{c}1,156^{\star \star \star} \\
(0,229)\end{array}$ & $\begin{array}{l}-0,292 \\
(0,641)\end{array}$ & $\begin{array}{l}-0,215^{\star} \\
(0,119)\end{array}$ & $\begin{array}{l}0,636^{\star \star} \\
(0,270)\end{array}$ & $\begin{array}{c}0,077 \\
{[0,014]}\end{array}$ & $\begin{array}{c}0,929 \\
{[1,784]}\end{array}$ \\
\hline Tamanho (In do ativo total) & $\begin{array}{l}-0,236 \\
(0,152)\end{array}$ & $\begin{array}{c}0,817 \\
(0,529)\end{array}$ & $\begin{array}{l}-0,172^{\star \star} \\
(0,0763)\end{array}$ & $\begin{array}{l}-0,495^{\star \star \star} \\
(0,177)^{\star \star \star}\end{array}$ & $\begin{array}{l}-0,990^{\star} \\
{[3,423]}\end{array}$ & $\begin{array}{c}-1,313^{\star \star} \\
{[5,523]}\end{array}$ \\
\hline Alavancagem & $\begin{array}{c}0,006^{\star \star \star} \\
(0,002)\end{array}$ & $\begin{array}{c}-0,055^{\star \star \star} \\
(0,015)\end{array}$ & $\begin{array}{c}-0,011^{\star \star \star} \\
(0,003)\end{array}$ & $\begin{array}{c}0,007 \\
(0,002)\end{array}$ & $\begin{array}{c}0,043^{\star \star \star} \\
{[7,535]}\end{array}$ & $\begin{array}{l}0,062^{\star \star \star} \\
{[16,219]}\end{array}$ \\
\hline Constante & $\begin{array}{c}0,970 \\
(1,763)\end{array}$ & $\begin{array}{l}-7,923 \\
(6,831)\end{array}$ & $\begin{array}{c}4,759^{\star \star \star} \\
(1,056)\end{array}$ & $\begin{array}{l}5,280^{\star *} \\
(2,311)\end{array}$ & $\begin{array}{l}12,682^{*} \\
{[3,366]}\end{array}$ & $\begin{array}{l}13,203^{*} \\
{[3,351]}\end{array}$ \\
\hline \multicolumn{7}{|l|}{ Ajuste dos modelos } \\
\hline Teste de White & $886,48^{\star \star \star}$ & $88,35^{\star \star \star}$ & $52,82^{\star \star \star}$ & $340,75^{\star \star \star}$ & - & - \\
\hline Teste de F de Chow & $10,099^{\star \star \star}$ & $6,86^{\star \star \star}$ & $4,35^{\star \star \star}$ & $9,82^{\star \star \star}$ & - & - \\
\hline Teste de Breusch-Pagan & $327,83^{\star \star \star}$ & $12,65^{\star \star \star}$ & $8,38^{* \star *}$ & $392,52^{\star *}$ & - & - \\
\hline Teste de Hausman & $147,02^{\star \star \star}$ & $17,80^{\star *}$ & 9,860 & $44,20^{* \star *}$ & - & - \\
\hline Modelo & Fixo & Fixo & Aleatório & Fixo & - & - \\
\hline Número de casos & 1357 & 148 & 204 & 990 & - & - \\
\hline Empresas & 348 & 88 & 54 & 238 & - & - \\
\hline Critério de Akaike & 2372,476 & 305,392 & 335,717 & 1541,112 & - & - \\
\hline $\mathrm{F}$ & 18,233 & 10,720 & - & 23,092 & - & - \\
\hline Wald & - & - & 105,610 & - & - & - \\
\hline Sig. & $p<0,001$ & $p<0,001$ & $p<0,001$ & $p<0,001$ & - & - \\
\hline $\mathrm{R}^{2}$ & 0,867 & 0,951 & $0,520^{1}$ & 0,883 & - & - \\
\hline $\mathrm{R}^{2}$ ajustado & 0,820 & 0,862 & - & 0,844 & - & - \\
\hline
\end{tabular}


de empresas que adotaram práticas diferenciadas de governança e o valor de mercado das empresas com níveis baixos de tais práticas, corroborando a Hipótese 4c. Por fim, os resultados apontam que a reputação influencia de maneira significativa o valor de mercado das empresas com níveis mais baixos de governança, Mercado Tradicional e níveis 1 e 2, o que não ocorreu no Novo Mercado, levando-nos a corroborar a Hipótese 5.

Em relação aos resultados da moderação, cabe ressaltar que o teste de Arnold (1982) foi significativo para o coeficiente de agrupamento e para a densidade, e não para as outras duas variáveis, apesar de o valor da probabilidade do teste ter apontado para uma chance inferior a $20 \%$ de erro. Todavia, como tal teste perde precisão quando os coeficientes não são significativos, acreditamos que exista possibilidade de um erro Tipo II, o que nos levou a aceitar as hipóteses de moderação, com base na amplitude da diferença dos coeficientes, tal como pela significância nos grupos de baixa governança, em detrimento do Novo Mercado. De qualquer forma, para avaliar a robustez de tais resultados, adicionalmente fizemos o teste de moderação com base na interação entre as variáveis independentes e a variável moderadora, como propuseram Jaccard, Turrisi e Wan (1990), cujos resultados confirmaram a hipótese da moderação.

Para sintetizar os resultados encontrados neste estudo, na Figura 2, apresentamos graficamente a influência de cada uma das variáveis independentes no valor de mercado. Cada uma das linhas representa a relação entre os indicadores para cada um dos

\section{Figura 2 - Efeito das variáveis no valor de mercado, moderado pelo nível de governança}
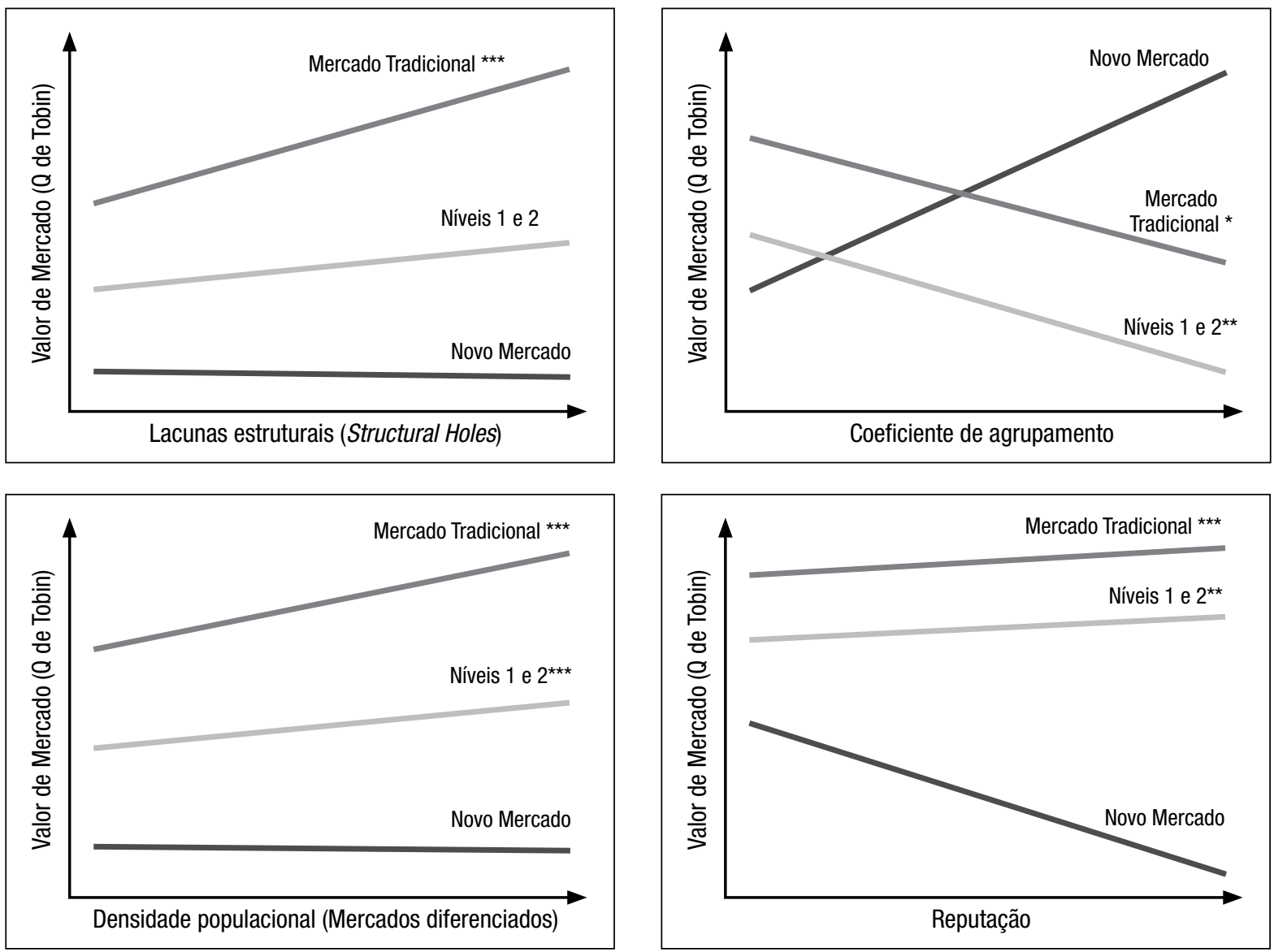

Legenda: ${ }^{* * *} p<0,01 \quad{ }^{* *} p<0,05 \quad{ }^{*} p<0,1$ 
níveis de governança. Nitidamente, a inclinação das retas demonstra que a influência das lacunas estruturais, da densidade e da reputação é maior entre as empresas do Mercado Tradicional e dos níveis 1 e 2 do que entre as empresas do Novo Mercado, em que um aumento no grau dessas variáveis leva a maior valor de mercado. Já no caso do coeficiente de agrupamento, enquanto tal indicador não é significativo entre as empresas do Novo Mercado, quanto maior a coesão do conselho em relação ao conselho de outras empresas, menor o valor de mercado.

\section{DISCUSSÃO E CONCLUSÃO}

Neste artigo, buscamos avaliar como as diferentes origens da legitimidade organizacional condicionam o desempenho das empresas listadas na BM\&F Bovespa com base em seu valor de mercado. Também analisamos como a adesão ao Novo Mercado, como mecanismo formal regulatório, modera o efeito da legitimidade organizacional no valor da empresa. Antes de tecer qualquer comentário acerca dos resultados, devemos destacar que a legitimidade reside na estrutura social, e, por causa disso, os aspectos relacionados a sua investigação empírica sempre são complexos. Para tanto, por causa da dificuldade de se acessarem aspectos estruturais e simbólicos, os estudos empíricos que envolvem a legitimidade sempre tendem a relacioná-la com suas origens (DEEPHOUSE e SUCHMAN, 2008). Apesar de essas origens serem diversas, nós as enquadramos analiticamente em três dimensões: a formal regulatória; a cultural-cognitiva; e a normativa. Entretanto, pelas razões expressas no quadro teórico utilizado, entendemos que cada uma das origens tem um efeito diferenciado no desempenho das empresas de capital aberto.

Os dados empíricos demonstraram que empresas que aderiram ao Novo Mercado da BM\&F Bovespa apresentam maior valor de mercado, indicando que os investidores pagam um valor adicional aos ativos dessas organizações, se comparados, na média, com ativos das outras empresas. Assim, entendemos que a adesão ao Novo Mercado funciona como uma certificação de boa conduta corporativa das organizações, como uma fórmula legitimadora. Tal fórmula legitima a atuação dessas organizações, assim como de seus artefatos (entre elas as ações), porque seu elemento de origem (a adesão voluntária a um grupo que respeita um conjunto de regras socialmente aceitas: Novo Mercado) é legitimado. Com efeito, se o mercado compreende que a organização faz referência a algum elemento legítimo, ela é tida como legítima. Sob a ótica da teoria institucional, podemos entender que aquelas organizações que buscaram se adequar a regras formalmente estabelecidas tiveram melhor desempenho, já que atuam de acordo com mitos racionalizadores (MEYER e ROWAN, 1977).

Acerca da legitimidade cultural-cognitiva, para a amostra como um todo, verificamos que somente o indicador de lacunas estruturais mostrou-se significativamente relacionado com o valor de mercado. Como apontamos na análise, por trás desse indicador de laços fracos do conselho, está o pressuposto de que o corpo de conselheiros e diretores tem importante função em prover a reputação da firma (PARSONS, 1956), que, por sua vez, também está relacionada com o fato de investidores decidirem se investem ou não em uma companhia atendo-se sempre à qualidade de seus gestores (MIZRUCHI, 1996).

Como elemento normativo, a reputação mostrou-se significativamente relacionada com o valor de mercado, o que corrobora outros estudos que apontam a importância da aceitação generalizada da organização diante da sociedade (DEEPHOUSE e CARTER, 2005; FOMBRUN e SHANLEY, 1990), indo ao encontro do pressuposto de que o sentimento de aceitação da organização perante sua audiência facilita seu acesso a recursos (MEYER e SCOTT, 1983).

Por fim, avaliamos se a legitimidade formal regulatória, operacionalizada pela presença no Novo Mercado, tem efeito moderador nas outras origens da legitimidade. Para tanto, separamos a amostra em três grupos: um de empresas presentes no Novo Mercado; outro com empresas dos níveis 1 e 2; e o Mercado Tradicional. Com base nos grupos formados, comparamos a influência dos indicadores da legitimidade cultural-cognitiva e da legitimidade normativa no valor de mercado. Como esperávamos, nos grupos em que o mecanismo formal relacionado a regras mais rígidas de governança corporativa estava ausente, houve influência destacada das outras origens da legitimidade no valor de mercado, enquanto no grupo de empresas do Novo Mercado não houve influência significativa. Como os resultados demostraram, quanto menor o grau de governança corporativa, maior a influência de aspectos normativos e cultural-cognitivos no desempenho dessas organizações.

Olhando individualmente para os indicadores, 
verificamos que as lacunas estruturais dos conselhos exercem influência no valor de mercado somente entre as empresas que fazem parte do Mercado Tradicional. Tal resultado aponta que, na ausência de outros mecanismos formais de governança que garantam a gestão da empresa dentro de algumas normas aceitas no mercado, os investidores valorizam empresas que têm conselheiros com mais prestígio. No caso da influência da coesão por meio do coeficiente de agrupamento, o resultado foi bem diferente do esperado: enquanto a coesão do conselho não tem influência significativa entre empresas do Novo Mercado, ela afeta negativamente o valor da empresa nos dois outros mercados. Esse resultado pode ser evidência de uma resposta dos investidores acerca de tentativas de algumas organizações em serem demasiadamente oportunistas ao buscar acesso a recursos e prestígio por meio dos relacionamentos. Além disso, a proximidade exagerada pode também ser percebida como privilégio para alguns grupos, em termos de informação.

No contexto brasileiro, tais achados podem ser interpretados com base em algumas características culturais, como o personalismo: no quadro atual, em que há tentativa de diminuir as influências personalistas sobre o mercado acionário, organizações que se estruturam em feudos (alto coeficiente de agrupamento) tendem a ser vistas com desconfiança, o que afeta o seu valor de mercado. Acerca da densidade organizacional, verificamos que o aumento no número de organizações com níveis mais altos de governança pode estar associado a um aumento na crença de que todas as organizações estão melhorando suas práticas de governança, o que contribuiu para o aumento do valor de mercado daquelas empresas presentes nos mercados com níveis menores de exigência. Por exemplo, como apontam Mendes-da-Silva e outros (2009) e Silveira, Barros e Famá (2006), muitas organizações vêm aprimorando seus mecanismos internos de governança, mesmo sem participar dos níveis formais do mercado da BM\&F Bovespa. Por fim, verificamos que a reputação influenciou positivamente o valor de mercado das empresas que fazem parte dos níveis 1 e 2 e do Mercado Tradicional, não sendo tal influência significativa entre as empresas do Novo Mercado. Tal resultado demonstra que o consentimento a critérios socialmente legítimos está diretamente relacionado com maior valorização das organizações, principalmente entre aquelas que não apresentam garantias formais de suas práticas de governança, o que vai ao encontro da hipótese do efeito moderador da legitimidade formal regulatória.

\section{Implicações teóricas e práticas}

A primeira delas envolve o fato de que elementos institucionais presentes no ambiente condicionam o desempenho organizacional. Organizações não respondem somente a pressões instrumentais, elas também se adequam a pressões institucionais, já que necessitam da aprovação social e de legitimidade para adquirir recursos. Mostramos, neste trabalho, que realmente tais fatores importam. Empresas cujos objetos são legitimados no ambiente são mais valorizadas. A segunda implicação teórica remete à natureza multifacetada da legitimidade. Apesar de Scott (1995) apontar que a distinção entre as diferentes dimensões da legitimidade é somente analítica, empiricamente elas se diferenciam (vide o próprio autor, em SCOTT e outros, 2000). Isso ocorre porque a legitimidade, como dimensão estrutural incorporada em agentes e objetos, absorve a legitimidade de sua origem. Sendo assim, se a legitimidade pode variar em cada origem, sua influência nas organizações também pode. Por fim, a última implicação teórica deste trabalho envolve a interação entre as diferentes dimensões da legitimidade: o fato de as organizações presentes no mercado acionário brasileiro terem sua atividade assegurada por um mecanismo formal de certificação levou as outras origens da legitimidade a terem papel nulo ou reduzido no valor de mercado, demonstrando que a influência de cada uma das origens nas organizações é condicionada pelas outras. Entre as implicações práticas, a fundamental delas remete à necessidade de os gestores corporativos das organizações repensarem a organização para além de sua função econômica, cujo objetivo, nas empresas de capital aberto, é a maximização do investimento do acionista. Executivos têm que atentar para o fato de que organizações legitimadas perante sua audiência tendem a ter maior facilidade de acessar recursos e, provavelmente, conseguem passar por crises com menor dificuldade, o que lhes possibilita maiores chances de valorização.

\section{Recomendações de estudos futuros}

A primeira recomendação que faremos envolve a necessidade de se investigar o processo de institucionalização das práticas de governança corporativa no Brasil, já que ela surgiu em países com mercados 
estruturados de modo totalmente diferente. Seria interessante, também, investigar como as organizações interpretam tal fenômeno, assim como elas respondem à pressão por adequação de sua gestão corporativa. Não poderíamos deixar de mencionar a necessidade de se compreender melhor o efeito negativo da rede de conselheiros, pois verificamos que o comportamento oportunista das organizações em buscar acesso a recursos por meio da coesão de suas relações as pune com menor valor de mercado. Estudos futuros poderiam buscar avaliar a reputação por meio de escores multidimensionais, como fizeram Fombrun e Shanley (1990). Outras variáveis também poderiam ser inseridas, por exemplo, indicadores relacionados à mídia, à responsabilidade social e ambiental. Por fim, questões relacionadas à causalidade da relação entre board interlocking, reputação e desempenho poderiam ser discutidas, pois há sérias dúvidas na literatura a respeito de quais os mecanismos operantes na relação entre esses elementos.

\section{NOTA DO AUTOR}

Versão preliminar deste artigo foi congratulada com $01^{\circ}$ Lugar no Prêmio IBGC Itaú de Governança Corporativa de 2010, Categoria Academia.
BLACK, B. S; CARVALHO, A. G; GORGA, E. What matters and for which firms for corporate governance in emerging markets? Evidence from Brazil (and other BRIK countries). Journal of Corporate Finance, v. 18, n. 4, p. 934-952, 2012.

BLACK, B. S; KIM, W. The effect of board structure on firm value: a multiple identification strategies approach using Korean data. Journal of Financial Economics, v. 104, n. 1, p. 203-226, 2012.

BLAIR, M. M. Ownership and control: re-thinking corporate governance for the twenty-first century. Washington: Brookings Inst, 1995.

BOLSA DE VALORES DE SÃO PAULO. Governança corporativa: comparativo entre segmentos. São Paulo: Bovespa, 2009. Disponível em: http://www.bovespa.com.br. Acesso em 05.10.2009.

BORGATTI, S. P. Structural holes: unpacking Burt's redundancy measures. Connections, v. 20, n. 1, p. 35-38, 1997.

BURT, R. S. Structural boles: the social structure of competition. Cambridge: Harvard University, 1992.

CAPRON, L; GUILLÉN, M. National corporate governance and post acquisition target reorganization. Strategic Management Journal, v. 30, n. 8, p. 803-833, 2009.

CARRUTHERS, B. G; KIM, J. The sociology of finance. Annual Review of Sociology, v. 37, p. 239-259, 2011.

CARTON, R. B; HOFER, C. W. Measuring organizational performance: metrics for entrepreneurship and strategic management research. Cheltenham: Eduard Elgar, 2006.

CARVALHAL-DA-SILVA, A. L; LEAL, R. P. C. Corporate governance index, firm valuation and performance in Brazil. Revista Brasileira de Finanças, v. 3, n. 1, p. 1-18, 2005.

CARVAlHO, A. G; PENNACCHI, G. G. Can a stock exchange improve corporate behavior? Evidence from firms' migration to premium listings in Brazil. Journal of Corporate Finance, v. 18, n. 4, p. 883-903, 2012.

CHUNG, K. H; PRUITT, S. W. A simple approximation of Tobin's q. Financial Management, v. 23, n. 3, p. 70-74, 1994.

COHEN, B. D; DEAN, T. J. Information asymmetry and investor valuation of IPOs: top management team legitimacy 
as a capital market signal. Strategic Management Journal, v. 26, n. 7, p. 683-690, 2005.

CERTO, S. T.; HODGE, F. Top Management Team Prestige and Organizational Legitimacy: An Examination of Investor Perceptions. Journal of Managerial Issues, v. 19, n. 4 , p. 461-477, 2007.

DAVIS, G. F. The significance of board interlocks for corporate governance. Corporate Governance: An International Review, v. 4, n. 3, p. 154-159, 1996.

DEEDS, D. L; MANG, P. Y; FRANDSEN, M. L. The influence of firms and industries legitimacy on the flow of capital into high-technology ventures. Strategic Organization, v. 2, n. 1, p. 9-34, 2004.

DEEPHOUSE, D. L; CARTER, S. M. An examination of differences between organizational legitimacy and organizational reputation. Journal of Management Studies, v. 42, n. 2, p. 329-360, 2005.

DEEPHOUSE, D. L; SUCHMAN, M. Legitimacy in organizational institutionalism. In: GREENWOOD, R; OLIVER, C; SAHLIN, K; SUDDABY, R. (Eds). The Sage Handbook of Organizational Institutionalism. London: Sage, 2008. p. 49-77.

FISS, P. C. Institutions and corporate governance. In: GREENWOOD, R; OLIVER, C; SAHLIN, K; SUDDABY, R. (Eds). The Sage Handbook of Organizational Institutionalism. London: Sage, 2008. p. 389-410.

FLIGSTEIN, N.; CHOO, J. Law and corporate governance. Annual Review of Law and Social Science, v. 1, p. 61-84, 2005.

FOMBRUN, C; SHANLEY, M. What's in a name? Reputation building and corporate strategy. Academy of Management Journal, v. 33, n. 2, p. 233-258, 1990.

GALASKIEWICZ, J. Interorganizational relations. Annual Review of Sociology, v. 11, p. 281-304, 1985.

GORGA, E. A cultura brasileira como fator determinante na governança corporativa e no desenvolvimento do mercado de capitais. Revista de Administração da USP, v. 39, n. 4, p. 309-326, 2004.

GREENE, W. H. Econometric analysis. 4. ed. Upper Saddle River: Prentice-Hall, 2000.
GRÜN, R. A sociologia das finanças e a nova geografia do poder no Brasil. Tempo Social, v. 16, n. 2, p. 151-176, 2004.

HANNAN, M. T; CARROL, G. R. Dynamics of organizational populations: density, legitimation, and competition. New York: Oxford University, 1992.

HIGGINS, M. C; GULATI, R. Stacking the deck: the effects of top management backgrounds on investor decisions. Strategic Management Journal, v. 27, n. 1, p. 1-25, 2006.

JACCARD, J; TURRISI, R; WAN, C. K. Interaction effects in multiple regression. Newbury Park: Sage, 1990.

KALBERG, S. Max Weber's types of rationality: cornerstones for the analysis of rationalization process in history. American Journal of Sociology, v. 85, n. 5, p. 1145-1179, 1980.

KIRSCHBAUM, C; GUARIDO FILHO, E. R. Perspectivas sociológicas da estratégia em organizações: uma introdução ao fórum. Revista de Administração Mackenzie, v. 12, n. 6, p. 14-27, 2011.

LAMEIRA, V. J; NESS JUNIOR, W. L; MACEDO-SOARES, T. D. L. V. A. Governança corporativa: impactos no valor das companhias abertas brasileiras. Revista de Administração da USP, v. 42, n. 1, p. 64-73, 2007.

LA PORTA, R; LOPEZ-DE-SILANES, F; SHLEIFER, A; VISHNY, R. Law and finance. Journal of Political Economy, v. 106, n. 5, p. 1113-1155, 1998.

LI, K; PRABHALA, N. R. Self-selection models in corporate finance. In: ECKBO, B. E. Handbook of Corporate Finance. Netherlands: Elsevier, 2007. v. 1, p. 39-86.

LIN, N. Social capital: a theory of social structure and action. Cambridge: Cambridge University, 2001.

MENDES-DA-SILVA, W. Small worlds and board interlocking in Brazil: a longitudinal study of corporate networks, 1997-2007. Revista Brasileira de Finanças, v. 9, n. 4, p. 521-548, 2011.

MENDES-DA-SILVA, W; FERRAZ-ANDRADE, J. M; FAMÁ, R; MALUF FILHO, J. A. Disclosure via website corporativo: um exame de informações financeiras de governança no mercado brasileiro. RAE-Revista de Administração de Empresas, v. 49, n. 2, p. 190-205, 2009. 
MENDES-DA-SILVA, W; ROSSONI, L; MARTIN, D. L; MARTELANC, R. A influência das redes de relações corporativas no desempenho das empresas do Novo Mercado da BOVESPA. Revista Brasileira de Finanças, v. 6, n. 3, p. 337-358, 2008.

MEYER, J. W; ROWAN, B. Institutionalized organizations: formal structure as myth and ceremony. American Journal of Sociology, v. 83, n. 2, p. 340-363, 1977.

MEYER, J. W; SCOTT, W. R. Centralization and the legitimacy problems of local government. In: MEYER, J. W; SCOTT, W. R. Organizational environments: ritual and rationality. Beverly Hills: Sage, 1983. p. 199-215.

MIZRUCHI, M. S. What do interlocks do? An analysis, critique, and assessment of research on interlocking directores. Annual Review of Sociology, v. 22, p. 271-298, 1996.

PARSONS, T. Suggestions for a sociological approach to the theory of organizations-I. Administrative Science Quarterly, v. 1, n. 1, p. 63-85, 1956.

PFEFFER, J; SALANCIK. The external control of organizations: a resource dependence perspective. New York: Harper \& Row, 1978.

PROCIANOY, J. L; VERDI, R. S. Adesão aos novos mercados da BOVESPA: Novo Mercado, Nível 1 e Nível 2 - determinantes e consequências. Revista Brasileira de Finanças, v. 7, n. 1, p. 107-136, 2009.

RIBEIRO NETO, R. M; FAMÁ, R. Uma alternativa de crescimento para o mercado de capitais brasileiro: o Novo Mercado. RAUSP-Revista de Administração da USP, v. 37, n. 1, p. 29-38, 2002.

ROBERTS, P. W; DOWLING, G. R. Corporate reputation and sustained superior financial performance. Strategic Management Journal, v. 23, n. 12, p. 1077-1093, 2002.

ROSSONI, L; MACHADO-DA-SILVA, C. L. Institucionalismo organizacional e práticas de governança corporativa. Revista de Administração Contemporânea, v. 14, edição especial, p. 173-198, 2010.

RUEF, M. A sociological perspective on strategic organization. Strategic Organization, v. 1, n. 2, p. 241-251, 2003.

RUEF, M; SCOTT, W. R. A multidimensional model of organizational legitimacy: hospital survival in changing ins- titutional environments. Administrative Science Quarterly, v. 43, n. 4, p. 877-904, 1998.

SANTOS, R. L; SILVEIRA, A. M. Board interlocking no Brasil: a participação de conselheiros em múltiplas companhias e seu efeito sobre o valor das empresas. Revista Brasileira de Finanças, v. 5, n. 2, p. 125-163, 2007.

SANTOS, R. L; SILVEIRA, A. M; BARROS, L. A. Board interlocking in Brazil: directors' participation in multiple companies and its effect on firm value and profitability. Latin American Business Review, v 13, n. 1, p. 1-28, 2012.

SCOTT, W. R. Institutions and organizations. Thousand Oaks: Sage, 1995.

SCOTT, W. R; RUEF, M; MENDEL, P. J; CARONNA, C. A. Institutional change and bealthcare organizations: from professional dominance to managed care. Chicago: University of Chicago, 2000.

SILVEIRA, A. M. Governança corporativa e estrutura de propriedade: determinantes e relação com o desempenho das empresas no Brasil. São Paulo: Saint Paul Institute of Finance, 2006.

SILVEIRA, A. M; BARROS, L. A. B. C; FAMÁ, R. Atributos corporativos, qualidade da governança corporativa e valor das companhias abertas no Brasil. Revista Brasileira de Finanças, v. 4, n. 1, p. 1-30, 2006.

SILVEIRA, A. M; LEAL, R. P. C; BARROS, L. A. B. C; CARVALHAL-DA-SILVA, A. L. Endogeneity of Brazilian corporate governance quality determinants. Corporate Governance, v. 10, n. 2, p. 191-202, 2010.

SUCHMAN, M. C. Managing legitimacy: strategic and institutional approaches. Academy of Management Review, v. 20, n. 3, p. 571-610, 1995.

WINTOKI, M. B; LINCK, J. S; NETTER, J. M. Endogeneity and the dynamics of internal corporate governance. Journal of Financial Economics, v. 105, n. 3, p. 581-606, 2012. 